Tetrahedron Letters No. 26, pp. 2367-2370, 1971. Pergamon Press. Printed in Great Britain.

\title{
MASS SPICTROMBPRY OF FRUCTOSE CONTAINING OLIGOSACCHARIDES
}

\author{
J.P. Kamerling and J.F.G. Vliegenthart \\ Laboratory of Organio Chemistry \\ University of Utrecht, The Netherlands \\ J. Vink and J.J. de Ridder \\ Jaboratory of Analytical Chemistry \\ University of Utrecht, The Netherlands
}

(Received in UK 17 Kay 1971; accepted in UK for publication 26 May 1971)

In our studies on the structure determination of oligosaccharides by mass spectrometry, we observed that hexosyl oligosaccharides containing fructose units behaved differently to those consisting of aldohexoses only. The mass spectmum of pertrimethylsilyl-sucrose ${ }^{*}$ (II) shows the presence of the fragment ion at m/ $437\left(\mathrm{C}_{17} \mathrm{H}_{41} \mathrm{O}_{5} \mathrm{Si}_{4}\right)$ with a rather high abundance compared to the peak at m/e 435 (figure 1). In the spectra of TMS-disaccharides containing only aldohexoses the relative intensity of the peak at $\mathrm{m} / \mathrm{e} 437$ is always smaller than that of the peak at $\mathrm{m} / \mathrm{e} 435^{\text {? }}$.

The usefulness of the fragment ion at $\mathrm{m} / \mathrm{e} 437$ or its analogue at $\mathrm{m} / \mathrm{e} 815$ as described below, for the characterization of fructose containing oligosaccharides may be 1 liustrated by the 14 examples given in Table $\mathrm{A}$.

In the mass spectra of TwS-aldohexosyl-(1 $\rightarrow 1)$ - or $(1 \rightarrow 2)$-fructoses the peak at m/e 437 has a high intensity. For the components with the glycosidic bond located on the remaining positions viz. $1 \rightarrow 3,1 \rightarrow 4,1 \rightarrow 5$ or $1 \rightarrow 6$, the intensity of $\mathrm{m} / \mathrm{e} 437$ is about the same as in the TMS-aldohexosyl-aldohexoses. However, these fructose containing disaccharides are characterized by the presence of a peak at $\mathrm{m} / \mathrm{e} 815$ ( $\mathrm{M}^{+}$ minus ${ }^{\circ} \mathrm{CH}_{2}$ OTMS) being high in comparison to the peak at $\mathrm{m} / \mathrm{e} 813$ ( $\mathrm{M}^{*}$ minus $^{\circ} \mathrm{CH}_{3}$ minus TMSOH). The formation of $\mathrm{m} / \mathrm{e} 815$ and $\mathrm{m} / \mathrm{e} 813$ in these disaccharides seems to be equivalent to the formation of $\mathrm{m} / \mathrm{e} 437$ and $\mathrm{m} / \mathrm{e} 435 \mathrm{in}$ monosaccharides 2,3 . In the latter case the relative intensities of the peaks at $\mathrm{m} / \mathrm{e} 437$ and $\mathrm{m} / \theta 435$ can be used to distinguish 2-ketohexoses from aldohexoses 4,5 .

The formation of the fragment ion at $\mathrm{m} / \mathrm{e} 437$ in $1 \rightarrow 1$ disaccharides results from the cleavage of the bond between $\mathrm{C} 1$ and $\mathrm{C} 2$ of the fructose unit, corresponding to the elimination of ${ }^{\circ} \mathrm{CH}_{2}$ OTMS in TWS-fructose ${ }^{5}$. For $1 \rightarrow 2$ disaccharides, we suggest the following fragmentation (figure 2), via pertrimethylailyl-fructose as an intermediate. 


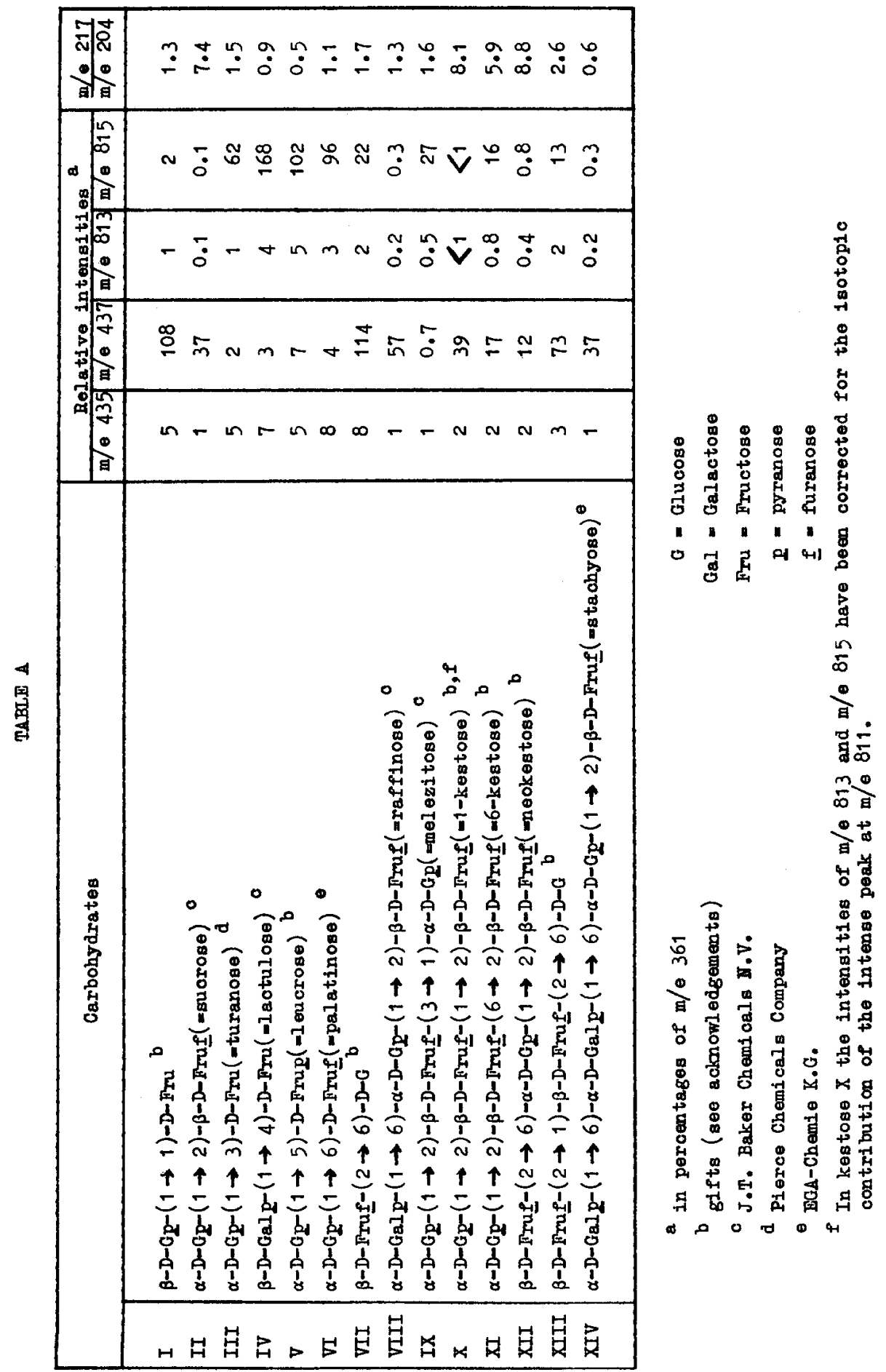




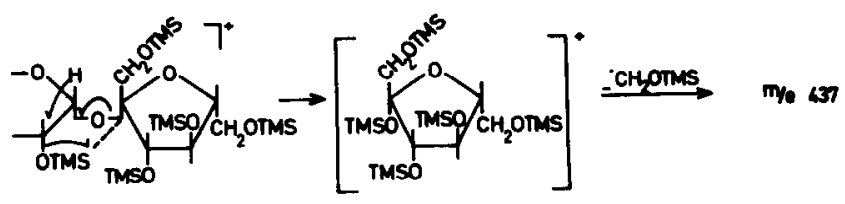

figure 2

However, an ion at $\mathrm{m} / \mathrm{e} 540$ corresponding to this intermediate was not present in a sigaificant abundance.

The mass speotrum of TMS- $\beta-D$-fruotofuranosyl- $(2 \rightarrow 6)$-D-gluoose (VII) also shows an intense peak at $\mathrm{m} / \mathrm{e}$ 437. However, in the Tus-aldohexosyl- $(1 \rightarrow 6)$-aldohexoses this peak bas a low intensity (m/e $437<\mathrm{m} / \mathrm{e} 435)^{1}$. These observationg make it highly probable that bonding of fructose via C2 gives rise to the formation of an intense peak at $\mathrm{m} / \mathrm{e} 437$, independent of the position of the connection in the other carbohydrate unit (Pigure 3).

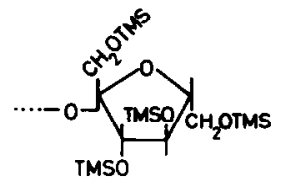

Pigure 3

On the besis of these results the mase spectre of tri- and tetra-secoherides (VIII to XIV) can be interpreted. The occurrence of the peak at $\mathrm{m} / \mathrm{e} 437$ in all these sugars with the exception of melezitose (IX) can be explained by the presence of a $(x \rightarrow 2)$-D-fructofuranose unit at one end of the molecule. The intense peak at $\mathrm{m} / \mathrm{e} 815$ $\left(\mathrm{C}_{32} \mathrm{H}_{75}{ }_{10} \mathrm{Si}_{7}\right)$ in IX, XI and XII originates from a $(x \rightarrow 2)$-D-fruotofuranose unit substituted by a hexose on one of the remaining positions of fructose. The mass speotrum of kestose $X$ reveals the presence of a peak at m/e 815 of an unexpeotedly low Intensity. The other fragmentations in kestose $x$ leading to a characteriatic peak at m/e 811 (m/e 829 minus $\mathrm{H}_{2} \mathrm{O}$; metastable peak at 793,4 ; eraot mass measurements gtve the

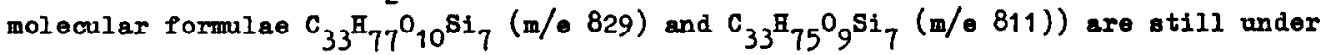
invertigation.

In monosaccharides, pyranose and furanose ringforms can be distinguished on the basis of the ratio of the peak intensities at $\mathrm{m} / \mathrm{e} 217$ (TMSO-CH=CH-C̈H-OMS) and $\mathrm{m} / \mathrm{e} 204$ (TMSO-CH- $\dot{C} H$-OTMS) being $>1$ for the furanose ring and $<1$ for the pyranose ring 4,5 . The Intensities of the peaks at $\mathrm{m} / \mathrm{e} 217$ and $\mathrm{m} / \mathrm{e} 204 \mathrm{in}$ oligosaccharides result from contributions of each of the constituent monosacoharides, whereas the type of glyoogidic linkage also plays a definite role ${ }^{1}$. The ratios of the intensities of the peaks at $\mathrm{m} / \mathrm{e} 217$ and $\mathrm{m} / \mathrm{e} 204$ of $\mathrm{I}$ to XIV are presented in Table 4 . Fvidently, the 


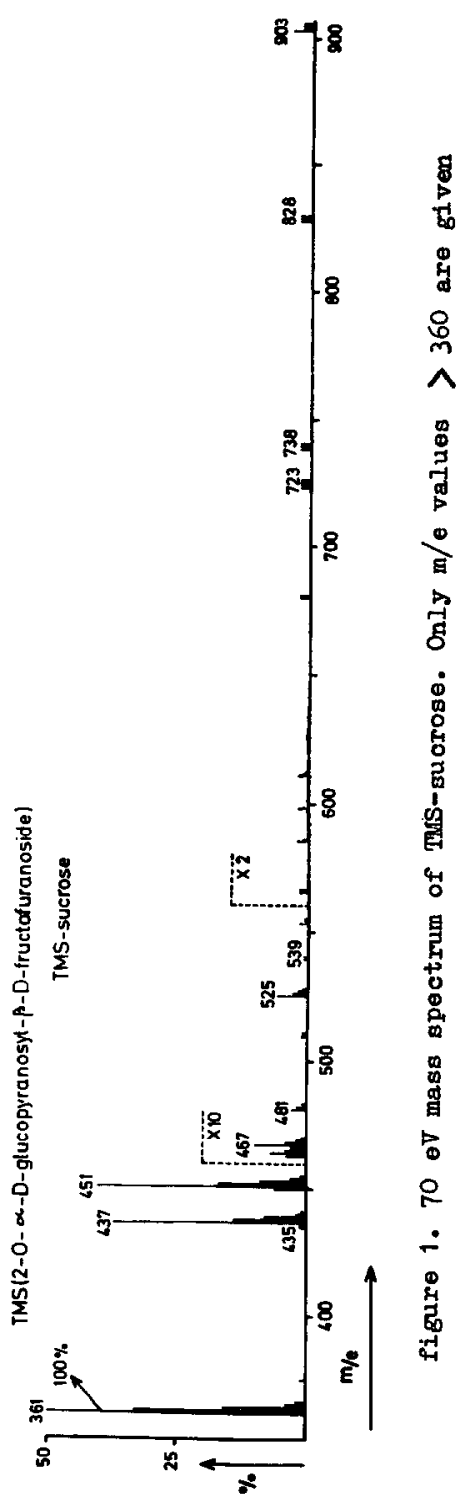

fructofuranose unit greatly influences this ratio. When a ereater series of these data is available, this ratio may be helpful in struotural determinations.

In this paper we have shown the importance of the peaks $\mathrm{m} / \mathrm{e} 437, \mathrm{~m} / \mathrm{e} 815, \mathrm{~m} / \mathrm{e} 204$ and $\mathrm{m} / \mathrm{e} 217$ for the structural determination of fructose containing oligosaccharides. Hore details will be published elsewhere.

Ereparation of the trimethylsilyl derivatives: $0.5 \mathrm{mg}$ of an oligosaccharide was dissolved in $1 \mathrm{ml}$ of pyridine. Subsequently $0.2 \mathrm{ml}$ of heramethy disilazane (BMDS) and $0.1 \mathrm{ml}$ of trimethylchlorogilane (TMCS) were added. After two hours at room temperature for disaccharides and 3 hours at $70^{\circ} \mathrm{C}$ for higher oligosaccharides $2 \mathrm{ml}$ of hexane and $2 \mathrm{ml}$ of water were added to the turbid mixture. The two layer system was strongly agitated and the waterlayer was then removed. The hexane-layer was washed with $1 \mathrm{ml}$ of water, dried over anhydrous $\mathrm{Na}_{2} \mathrm{SO}_{4}$ and evaporated in vacuo. The residue was dissolved in $1 \mathrm{ml}$ of hexane. If the oligosaccharide did not dissolve easily in pyridine, a very small drop of water was added before the addition of pyridine. In this cese $0.6 \mathrm{ml}$ of HMDS and $0.3 \mathrm{ml}$ of TiCS was used. Reducing oligosaccharides were anomerized in water during 48 hours at room temperature. $10 \mu \mathrm{pl}$ of this solution was used for mass spectrometry.

Acknowledgements: We thank Dr. F. Arcamone (Milan), Dr. F.H. Stodola (Peoria, Illinois), Dr. R.W.Bailey (Palmerston North), Dr. J.S.C. Bacon (Aberdeen), Dr. M. Trojna (Prag) and Dr. W. Kahl (Krakow) for the eifts of carbohydrates. This investigation was supported by the Netherlands Foundation for Chemical Research (SON) with Iinancial aid from the Netherlands Organization for the Advancement of Pure Research (zwO).

References

1. J.P. Kamerling, J.F.G. Vilegenthart, J. Vink and J.J. de Ridder, Tetrahedron, in press

2. D.C. DeJ ongh, T. Radford, J.D. Hribar, S.Hanessian, M. Bieber, G. Dawson and C.C. Sweeley, J. Am. Chem. Soc. 21, 1728 (1969)

3. N.K. Kochetkov, O.S. Chizhov and N.V. Molodtsov, Tetrahedron 24, 5587 (1968)

4. H.C. Curtius, M. Müller and J.A. Völlmin, J. Chromatog. 37, 216 (1968)

5. S. Karady and S.H. Pines, Tetrahedron 26, 4527 (1970) 